\title{
An Overview of Smart Grid Technology with its Present Situation and Anticipation in the Asian Region
}

\author{
Md. Musa Ali Reza ${ }^{1}$, Tawsif Hyder$^{2}$, Md. Mahfuzur Rahman ${ }^{3}$, Alif Shahriar ${ }^{4}$ \\ ${ }^{1,4}$ Department of Electrical \& Electronic Engineering, American International University BANGLADESH \\ ${ }^{2,3}$ Department of Electrical \& Electronic Engineering, Ahsanullah University of Science \& Technology, \\ BANGLADESH \\ *Corresponding Contact: \\ Email: md.musaalireza@yahoo.com \\ Cell Phone: +8801683690982
}

\begin{abstract}
Smart grid system is considered to be an important aspect in order to solve power issues and energy crisis. To explain smart grid technologies and the redistribution of smart grid in Asian region is the goal of this paper. The article gives an idea of the difficulties of present electricity grid and the possible ways of solving these difficulties using the vision of smart grid. The paper allows us to identify the comparison between the conventional grid system and the smart grid system. The essence of this vision is "a fully automated power delivery network that can ensure a two-way flow of electricity and information between the power plants and appliances and all points in between". It also provides the overview of Advance metering infrastructure, Personal energy management and Information Technology, which are the driving technological components of smart grid. The further explanation is about the comprehensive analysis of marching and upcoming projects as well as technologies on Smart Grid in Asian region. Finally, the paper concludes with the suggestions and proposals for the Regional Approach to Smart Grid Development. The article also explains the demand for Smart Grid capability within Asia which is quite diverse in nature ranging from reflecting the sophisticated nature of electricity demand in developed and developing nations of Asia.
\end{abstract}

Keywords: Smart Grid Characteristics; AMI; Communication networks; Smart grid in Asian region

\section{INTRODUCTION}

Many countries and electricity markets are looking at smart grid as advanced solution in delivering mix of enhanced values ranging from higher security, reliability and power quality, lower cost of delivery, demand optimization, and energy efficiency. Actually "Smart grid is an electricity network that can intelligently integrate the actions of all users connected to itgenerators and customers"(Globalsmartgridfederation.org/smartgriddef.html)]. Its advanced capabilities are demand optimization, delivery efficiency, and renewable energy optimization will lead to lower carbon footprint and overall lower energy cost and investment in energyrelated infrastructure. 
The fundamental drivers for Smart Grid are:

- Energy Efficiency

- Demand or Response

- Integrated Multi-Energy

- Revenue Protection

- Operational Efficiency

- Customer Satisfaction

\section{COMPARISON OF TODAY'S GRID vS. SMART GRID}

- Active participation by consumers- In today's grid customers is uninformed and nonparticipative with power system but in smart grid consumers are informed, involved and active.

- $\quad$ Power quality for the digital economy- Today's grid focuses on outages by showing slow response to power quality issues but in smart grid power quality is a priority with a variety of quality and price options.

- Assets and efficient operation- Today's grid uses little integration of operational data with asset management, but smart grid focuses on prevention, minimizing the impact on consumers.

- Natural disasters- Today's grid is vulnerable to malicious acts of terror and natural disaster but smart grid is resilient to attack and natural disaster with rapid restoration capabilities

\section{Smart Grid Characteristics}

Smart grid has recently been introduced to provide a smarter power grid via adding sensors and intelligent devices. These devices will collect data from the power grid. In a case of any problems, e.g., blackout, sometimes the smart grid is able to heal itself automatically. Oftentimes, the information collected from the power grid needs to be transmitted to the utilities (control centers), then according to the received information, the utilities will send commands to the power grid.

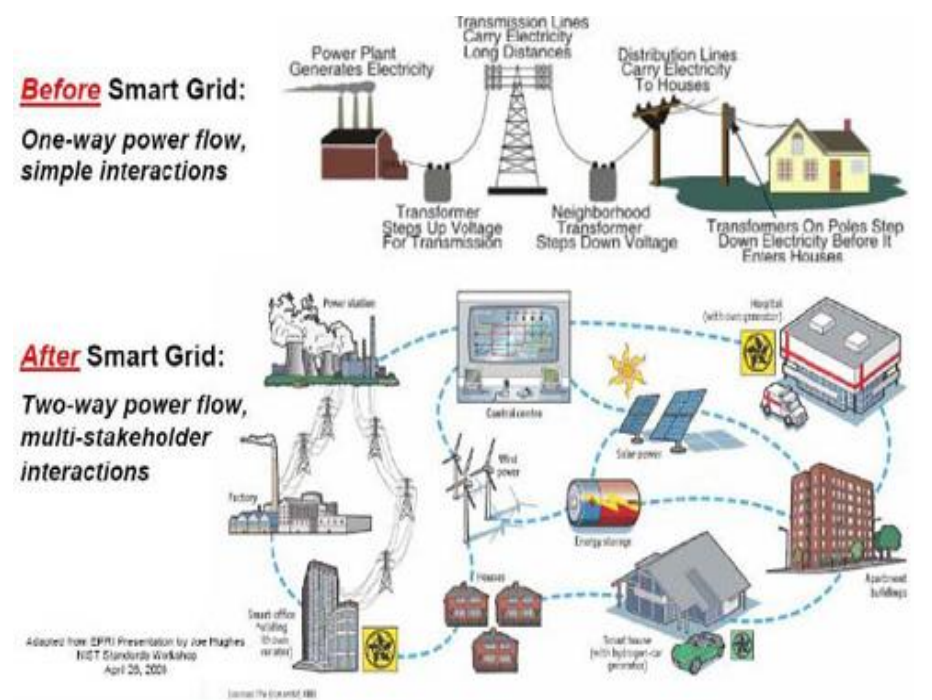

Figure 1: Smart grid (Belden.com/blog/industrialethernet/Smart-Grid-Lessons-for-IndustrialNetworks.cfm) 
In the smart grid, there is an attempt to follow the goals below (Burkhart, 2009):

- Customer participation: customers will receive price signals and adjust their electronic devices according to it. In addition, under the demand response program, some customers permit the utility companies to control their smart electric devices at home. Hence, utilities are allowed to turn the customers' devices off in case of emergency or during peak hours.

- Power quality for the 21st century: through monitoring the power factors such as current and voltage, the power workforces can identify the power grid problems.

- Integration of all generations and storage options: smart grid aims to integrate distributed electrical generations, e.g., micro grids and renewable energies with the power grid. Thus, managing the produced power would be easier.

- Self-healing: the power grid would be able to heal itself automatically. It can decide based on the collected data and react dynamically.

- Resilience against attacks and disasters: this characteristic can be provided by increasing power grid robustness, protecting critical assets from physical attacks and providing sufficient redundancy in the power grid (National Energy Technology Laboratory, 2009).

- Asset management and operational efficiency: quality of assets and how efficient they are working on the power grid will be monitored. For example, the cable temperature is measured.

- New markets and operations: smart grid will integrate and open new businesses to the power grid. For instance, it integrates IT infrastructure to the power grid; Smart devices are needed to be designed, and communication infrastructures are needed to be developed

The Primary smart grid services include:

- Vehicle to the power grid technology: vehicles store power during off-peak hours and send it back to the power grid during on- peak hours.

- Power grid monitoring: electrical properties such as voltage and current of the power grid infrastructures are monitored.

- Demand side management: it is comprised of two parts:

- Load shifting/demand response.

○ energy conservation, e.g., using energy efficient products

- $\quad$ Automatic meter reading.

\section{Vision OF the SMART GRID SyStem}

A growing recognition of the need to modernize the grid to meet tomorrow's challenges has found articulation in the vision of a Smart Grid. Multiple industry and research groups have created architectural blueprints for the evolution of today's power grid into a Smart Grid that share several common features.

The Smart Grid, as it is conceived today, will offer several benefits to utilities and consumers:

- It will provide utilities the ability to monitor and manage their power delivery down to the home or business in real time.

- Utilities can offer multiple rate structures to manage demand peaks and provide demand management services to encourage efficiency.

- It will allow utilities to delay the construction of new plants and transmission lines and better manage their carbon output through implementing measures such as demand response and time-based rates to manage load more actively. 
- It will allow utilities to provide real-time information to their customers and utility workers in the field, resulting in operational efficiencies and more reliable service.

- It will allow utilities more proactively to manage the integration of clean energy technologies into the grid to maximize their environmental benefits and operational value.

\section{Smart Grid Challenges}

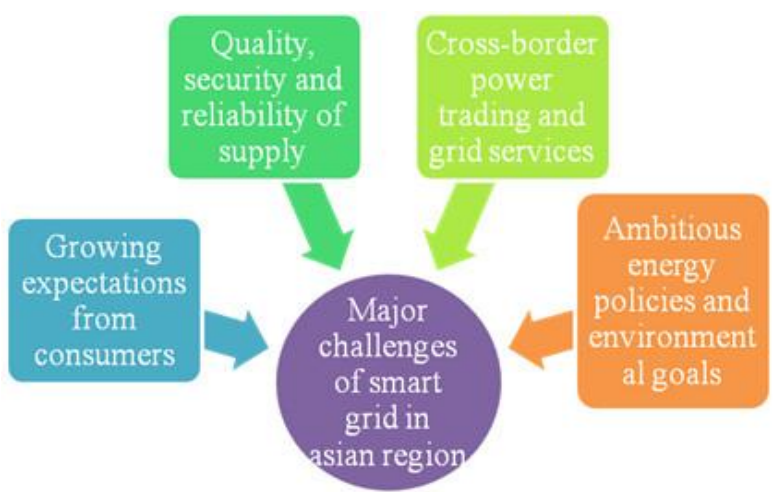

Figure 2: Challenges in Smart Grid

The above challenges can only be met if we move towards the future vision of the electricity system and making our electricity network "Smart". The user- specified quality; security and reliability of supply for the digital age can be achieved.

Harmonized legal frameworks are facilitating cross-border trading of power and grid services, extensive small and distributed generation connected close to ending customers all can be achieved. However all this is very far until and unless we move our approach towards Smart Grid. Now it is the time for revolutionizing the power sector by using Smart Grid that is almost as powerful as an internet, so that it would attract many attentions from various industries.

\section{The Idea of Advanced Metering Infrastructure in Smart Grid System}

Advanced metering infrastructure (AMI) is an automated architecture, two-way communication between a utility's smart meter with an IP address and a utility's head end systems. Providing utility companies with real-time data about power consumption is the goal of AMI.

The working procedure of AMI is given as follows:

AMI starts with Automated Meter Reading (AMR).

Smart meters automatically send their data to a local collection point. Local collection points forward the meter data to a central collection point.AMI kicks in when data reaches the central collection point, using powerful software to process the meter readings, manage supply and demand, and keep consumers happy.

In its most simplistic form,

- $\quad$ AMR uses the information to bill consumers, passing on cost savings achieved through automation.

- $\quad$ AMI uses the information to improve reliability and efficiency, detect faults (and remotely repair them where possible), create new rates and programs (such as timebased pricing). 
Power consumers through informed energy usage choices, and comply with government regulations. Also to Bill customers passing on cost savings achieved through all of the above.

AMI utilities provide customers with easy access to their usage and cost information, typically through dedicated monitoring hardware or by providing information over the Internet. That shows at a glance how much power is being consumed moment-to-moment and in total, allowing customers to make informed choices about the usage and associated costs:

- Utilities typically provide a number of pricing programs aimed at helping consumers reduce costs by using energy more efficiently (for example, at times when demand is lower).

- During emergencies or unexpected peak events, utilities can immediately inform consumers about the situation and recommend actions they should take. In some instances, AMI can remotely adjust customers usage (such as turning off air conditioning) to ensure power can continue to be delivered where it is needed most.

The two-way communication available through the AMI smart meters gives both utilities and consumers the ability to adjust and control usage remotely. Appliances and services that are compatible with the smart meters can form and be managed as a total integrated system.

\section{Communications Technologies aVailable for Smart Grids}

A communications system is the key component of the smart grid infrastructure (Gungor and Hancke, 2010; Gungor and Lambert, 2006; Laverty et al, 2010). With the integration of advanced technologies and applications for achieving a smarter electricity grid infrastructure, an enormous amount of data from different applications will be generated for further analysis, control, and real-time pricing methods. Hence, it is very critical for electric utilities to define the communications requirements and find the best communications infrastructure to handle the output data and deliver a reliable, secure and cost-effective service throughout the total system. Electric utilities attempt to get customer's attention to participate in the smart grid system, in order to improve services and efficiency. Demand side management and customer participation for efficient electricity usage are well understood. Furthermore, the outages after disasters in existing power structure also focus the attention on the importance of the relationship between electric grids and communications systems (Gungor and Hancke, 2010).

Different communications technologies supported by two primary communications media, i.e., wired and wireless, can be used for data transmission between smart meters and electric utilities. In some instances, wireless communications have some advantages over wired technologies, such as low-cost infrastructure and ease of connection to difficult or unreachable areas. However, the nature of the transmission path may cause the signal to attenuate. On the other hand, wired solutions do not have interference problems and their functions are not dependent on batteries, as wireless solutions do.

Two types of information infrastructure are needed for information flow in a smart grid system. The first flow is from a sensor and electrical appliances to smart meters, the second is between smart meters; and the utility's data centers. As suggested in [8], the first data flow can be accomplished through the power line communication or wireless communications, such as ZigBee, Z-wave, and others. For the second information flow, cellular technologies or the Internet can be used. Nevertheless, there are key limiting factors that should be taken into account in the smart metering deployment process, such as time of deployment, operational costs, the availability of the technology and rural/urban or indoor/outdoor environment, etc. The technology choice that fits one environment may not be suitable for 
the other. In the following, some of the smart grid communications technologies along with their advantages and disadvantages are briefly explained. An overview of smart grid communication technologies can be found in Table I.

Table I: Smart Grid Communications Technologies

\begin{tabular}{|l|l|l|l|}
\hline Technology & Spectrum & Data Rate & Coverage Range \\
\hline GSM & $900-1800 \mathrm{MHz}$ & Up to $14.4 \mathrm{Kbps}$ & $1-10 \mathrm{~km}$ \\
\hline GPRS & $900-1800 \mathrm{MHz}$ & Up to $170 \mathrm{kbps}$ & $1-10 \mathrm{~km}$ \\
\hline 3G & $1.92-1.98 \mathrm{GHz} 2.11-2.17 \mathrm{GHz}$ & $384 \mathrm{Kbps}-2 \mathrm{Mbps}$ & $1-10 \mathrm{~km}$ \\
\hline WiMAX & $2.5 \mathrm{GHz}, 3.5 \mathrm{GHz}, 5.8 \mathrm{GHz}$ & Up to $75 \mathrm{Mbps}$ & $10-50 \mathrm{~km}(\mathrm{LOS}) 1-5 \mathrm{~km}$ (NLOS) \\
\hline PLC & $1-30 \mathrm{MHz}$ & $2-3 \mathrm{Mbps}$ & $1-3 \mathrm{~km}$ \\
\hline ZigBee & $2.4 \mathrm{GHz}-868-915 \mathrm{MHz}$ & $250 \mathrm{Kbps}$ & $30-50 \mathrm{~m}$ \\
\hline
\end{tabular}

\section{ZigBee:}

ZigBee is a wireless communications technology that is relatively small in power usage, data rate, complexity and cost of deployment. It is an ideal technology for smart lighting, energy monitoring, home automation, and automatic meter reading. ZigBee and ZigBee Smart Energy Profile (SEP) have been realized as the most suitable communication standards for smart grid residential network domain by the U.S National Institute of Standards and Technology (NIST) (Zhong et al, 2011). The communication between smart meters, as well as among intelligent home appliances and in-home displays, is crucial. Many AMI vendors, such as Itron, Elster, and Landis Gyr, prefer smart meters that the ZigBee protocol can be integrated into (Gungor et al, 2011). ZigBee integrated smart meters can communicate with the ZigBee embedded devices and control them. ZigBee SEP provides utilities to send messages to the home owners, and home owners can reach the information about their real-time energy consumption.

\section{Wireless Mesh:}

A mesh network is a flexible system consisting of a group of nodes, where new nodes can join the group, and each node can act as an independent router. The self-healing characteristic of the network enables the communication signals to find another route via the active nodes if any node should drop out of the network. Especially, in North America, RF mesh- based systems are very popular. In PG\&E's Smart Meter system, every smart device is equipped with a radio module, and each of them routes the metering data through nearby meters. Each meter acts as a signal repeater until the collected data reaches the electric network access point. Then, collected data is transferred to the utility via a communication network. A private company, Sky Pilot Networks uses mesh networking for smart grid applications due to the redundancy and high availability features of mesh technology (Gungor et al, 2011).

\section{Power Line Communication:}

Power line communication (PLC) is a technique that uses the existing power lines to transmit high speed ( 2 - $3 \mathrm{Mbps}$ ) data signals from one device to the other. PLC has been the first choice for communication with the electricity meter due to the direct connection with the meter (Lewis et al, 2009). Also successful implementations of AMI in urban areas where other solutions struggle to meet the needs of utilities. PLC systems based on the LV distribution network have been one of the research topics for smart grid applications in China (Zhai, 2011). In a typical PLC system, smart meters are connected to the data concentrator through power lines and data is transferred to the data center via cellular network technologies. For example, any electrical device, such as a power line smart transceiver-based meter, can be connected to the power line and used to transmit the 
metering data to a central location. France has launched the "Linky meter project" that includes updating 35 million traditional meters to Linky smart meters (Solarcontrollercharger.com/with-smart-meters-trend-of-various-semiconductor-plctechnology-and-solutions/). PLC technology is chosen for data communication between the smart meters and the data concentrator while GPRS technology is used for transferring the data from the data concentrator to the utility's data center. ENEL, the Italian electric utility, chose PLC technology to move smart meter data to the nearest data concentrator and GSM technology to send the data to data centers.

\section{Marching and Upcoming Projects in Asia}

Energy markets in the Asia Pacific region are experiencing a period of significant growth and development. It drives both by expanding electricity demand as well as new opportunities for cleaner and more efficient power generation, transmission, and distribution. Investment in smart grid technologies by utilities and governments within Asia Pacific will rise at a healthy pace over the next several years, and the total smart grid market will increase from $\$ 11.9$ billion in 2011 to $\$ 28.8$ billion by 2017 ( Businesswire.com/news/home/20110630005464/en/Smart-Grid-Investment-Asia-PacificExceed-171). The cleantech market intelligence firm forecasts that cumulative smart grid investment in the region will reach $\$ 171.3$ billion by 2017.

China represents $70 \%$ of the Asian smart grid market and will invest close to US\$250 billion into its grid over the next five years (Greentechmedia.com/research/report/smartgrid-in-china-2012-2016). There are major plans in motion in the areas of transmission, distribution automation, smart meters, electric vehicles (EV), and EV charging technologies, and over 263 smart grid pilot projects already underway.

Japan invested around $\$ 849$ million in Smart Grid becoming the third highest Smart Grid investment making country in the world. The government also has planned to install smart meters across the country by 2020. Just like any other country, Japan has its priority for investing in Smart grids. South Korea is taking the green initiative by investing \$7.18 Billion into a Smart Grid in an effort to curb their country's CO2 Emissions and improve the efficiency of their electricity market. This major overhaul is headed up by Korea Electricity Power Corp (KEPCO), and they hope to have the project completed by 2030 (Cleantechnica.com/2011/02/24/south-korea-investing-7-18-billion-in-new-smart-grid/).

The ROC (Taiwan) government will invest NT\$130 billion (US\$4.36 billion) over the next 20 years to construct a nationwide smart grid, according to the Bureau of Energy under the Ministry of Economic Affairs (Taiwantoday.tw/ct.asp?xItem=195888\&ctNode=445).

\section{Conclusion and Proposals for a Better Power Network among the Asian Regions using Smart Grid}

To improve the service quality of the power delivery mechanism : it is easier to solve the limitation of the power transmission and distribution systems around the world .Countries like China, Japan, and South Korea has made unbelievable progress in the sector of Smart Grid and they have solved their energy crisis and power issues by using it . However some countries are far behind in establishing this idea of Smart Grid; thus they are still facing shortages of electric energy. Individual States in Asian Region face significant challenges in evaluating and shaping utility Smart Grid proposals since it represents a complex technical problem. Commission staffs, for the most part, do not have a personnel trained in this area and lack the 
finance resources needed to hire outside consultants. Without obtaining additional help, individual states run a significant risk of only responding to utility AMI agendas and forgoing any opportunity to move forward with their own Smart Grid agendas which could potentially create more competitive and robust market activity and substantially greater customer benefits. In order to overcome the energy shortages and the environmental concern in Asian region, an agreement should be made between the governments of different nations to establish the concept of regional Smart Grid.

\section{REFERENCES}

Belden.com/blog/industrialethernet/Smart-Grid-Lessons-for-Industrial-Networks.cfm

Businesswire.com/news/home/20110630005464/en/Smart-Grid-Investment-Asia-Pacific-Exceed-171

Cleantechnica.com/2011/02/24/south-korea-investing-7-18-billion-in-new-smart-grid/

D. M. Laverty, D. J. Morrow, R. Best, P. A. Crossley, "Telecommunications for Smart Grid: Backhaul solutions for the distribution network," IEEE Power and Energy Society General Meeting, pp. 16, 25-29 July 2010.

Globalsmartgridfederation.org/smartgriddef.html

Greentechmedia.com/research/report/smart-grid-in-china-2012-2016

L. A. Burkhart, "The DOE's "7 Traits of a Smart Grid"," Fortnightly's, vol. 70, 2009.

L. Wenpeng, D. Sharp, S. Lancashire, "Smart grid communication network capacity planning for power utilities," IEEE PES, Transmission and Distribution Conference and Exposition, pp.1-4, 19-22 April 2010.

M.Y. Zhai, "Transmission Characteristics of Low-Voltage Distribution Networks in China Under the Smart Grids Environment," IEEE Trans. on Power Delivery, vol.26, no.1, pp. 173-180, Jan. 2011.

National Energy Technology Laboratory, "Smart Grid Principal Characteristic: Operates Resiliently against Attack and Natural Disasters," Office of Electricity Delivery and Energy Reliability, 2009.

R. P. Lewis, P. Igic, and Z. Zhongfu, "Assessment of communication methods for smart electricity metering in the U.K.," in Proc. of IEEE PES/IAS Conference on Sustainable Alternative Energy (SAE), pp. 1-4, Sept. 2009.

Solarcontrollercharger.com/ with-smart-meters-trend-of-various-semiconductor-plc-technology-andsolutions/

Taiwantoday.tw/ct.asp? $x$ Item $=195888 \& c t N o d e=445$

V.C. Gungor, B. Lu, G.P. Hancke, “Opportunities and Challenges of Wireless Sensor Networks in Smart Grid," IEEE on Trans. Ind. Electron, vol. 57, no. 10, pp. 3557-3564, October, 2010

V.C. Gungor, D. Sahin, T. Kocak, and S. Ergüt, 'Smart Grid Communications and Networking,' Türk Telekom Technical Report-11316-01, April, 2011.

V.C. Gungor, F. C. Lambert, "A Survey on Communication Networks for Electric System Automation,"Computer Networks, vol. 50, pp. 877-897, May 2006.

Y. Pei Zhong, A. Iwayemi, C. Zhou, "Developing ZigBee Deployment Guideline Under WiFi Interference for Smart Grid Applications," IEEE Trans. on Smart Grid, vol.2, no.1, pp. 110-120, March 2011 